\title{
LOAD-DISPLACEMENT PROPERTIES OF LOWER CERVICAL SPINE MOTION SEGMENTS
}

\author{
Sean P. Moroney,* Albert B. Schultz,* James A. A. Miller* and \\ Gunnar B. J. Andersson† \\ * Department of Mechanical Engineering, University of Michigan, Ann Arbor, MI 48109-2125, U.S.A. \\ and + Department of Orthopacdic Surgery, Rush-Presbyterian Medical Center, Chicago, IL, U.S.A
}

\begin{abstract}
The load-displacement behavior of 35 fresh adult cervical spine motion segments was measured in compression, shear, flexion, extension, lateral bending and axial torsion tests. Motion segments were tested both intact and with posterior elements removed. Applied forces ranged to $73.6 \mathrm{~N}$ in compression and to $39 \mathrm{~N}$ in shear, while applied moments ranged to $2.16 \mathrm{Nm}$. For each mode of loading, principal and coupled motions were measured and stiffnesses were calculated. The effect of disc degeneration on motion segment stiffnesses and the moments required for motion segment failure were also measured.

In compression, the stiffnesses of the cervical motion segments were similar to those of thoracic and lumbar motion segments. In other modes of loading, cervical stiffnesses were considerably smaller than thoracic or lumbar stiffnesses. Removal of the posterior elements decreased cervical motion segment stiffnesses by as much as $50 \%$. Degenerated cervical discs were less stiff in compression and stiffer in shear than less degenerated discs, but in bending or axial torsion, no statistically significant differences were evident. Bending moments causing failure were an order of magnitude lower than those for lumbar segments.
\end{abstract}

\section{INTRODUCTION}

Knowledge of the load-displacement properties of the spine is useful in understanding its mechanical behavior and for investigating a number of spine pathologies. A basic mechanical unit of the spine is the motion segment, which consists of two adjacent vertebrae and their intervening soft tissues. Lysell (1969) studied the motion patterns of lower cervical motion segments without reference to the loads required to produce the motions. Earlier studies of human spine motion segments which have reported load-displacement properties have largely considered the motion segments of the thoracic and lumbar regions. For example, Virgin (1951), Hirsch and Nachemson (1954) and Brown et al. (1957) tested lumbar motion segments in compression. Markolf $(1970,1972)$ tested thoracic and lumbar motion segments in compression, shear, bending and axial torsion. Panjabi et al. (1976) tested thoracic motion segments in these modes as well as in tension. Lin et al. (1978) tested lumbar motion segments in shear and in axial and eccentric compression. Berkson et al. (1979) and Schultz et al. (1979) tested lumbar motion segments in compression, shear, bending and axial torsion. Tencer and Ahmed (1981) investigated the effects of secondary experimental variables on the measurement of the mechanical properties of lumbar motion segments. More recently, Panjabi et al. (1983) and Panjabi et al. (1986) tested cervical motion segments in shear, compression and tension. Zidel et al. (1985) tested cervical motion segments in tension, compression, shear, bending and axial torsion.

The cervical region of the spine differs from the lumbar and thoracic regions in that it bears less body

Received 11 August 1986; in revised form 2 February 1988. weight and is in general more mobile. On these grounds, the mechanical properties of its motion segments might be expected to differ from those of the lumbar and thoracic regions.

This paper reports the load-displacement behavior of 35 fresh human cadaver cervical spine motion segments tested in compression, shear, bending and axial torsion. Motions in response to these loads were measured and corresponding stiffnesses were computed for the principal motions. The influences of both the intervertebral disc level and the degree of degeneration were examined. Moments required to produce motion segment failure were measured. The influence of motion segment gross morphology was examined to determine to what extent it might explain variations in measured properties. The effect of a bony union of the facet joints, observed in two segments, was also explored.

\section{MATERIALS AND METHODS}

Thirty-five adult motion segments excised from 16 cervical spine sections were tested. The spine sections had been previously removed at autopsy within $24 \mathrm{~h}$ after death and stored at $-20^{\circ} \mathrm{C}$. Data regarding age, sex, medical history, or cause of death were not available for these specimens. In preparation for testing, muscular tissue was removed from each spine section before it was divided into individual motion segments. Each segment was visually examined and palpated for evidence of damage. In addition, the segments were radiographed in sagittal, transverse and coronal planes and the films were examined to insure that no fractures or evidence of other pathologies existed.

Segments were tested as 'intact segments' or as 'disc segments'. An intact segment was anatomically com- 
plete; a disc segment had posterior arches and ligaments excised, so that only the vertebral bodies, the intervertebral disc, and the adjacent longitudinal ligaments remained. Excision was not supervised directly by the authors. In 19 segments, the posterior arches were found to have been damaged during excision. The posterior elements were removed completely from these segments and they were tested only as disc segments. All other segments were first tested as intact segments. Then, either the posterior elements were removed and the segments were retested as disc segments, or the intact segments were tested to failure. All disc segments were eventually tested to failure.

Of the 35 segments tested, nine were from the $\mathrm{C} 2-3$, six from the C3-4, six from the C4-5, four from the C5-6, six from the C6-7 and four from the C7-T1 level. Two segments exhibited a bony union of the facet joints; only one of these was tested intact. After testing was completed, the discs were horizontally sectioned and visually graded for degree of degeneration, using the scheme of Nachemson (1960), from Grade 1 (degeneration-free) to Grade 4 (severely degenerated). Five discs were Grade 1, 13 were Grade 2, 11 were Grade 3 and six were Grade 4 . The mean degeneration grade was 2.5, with a standard deviation of 1.0. Central disc heights were measured from the lateral radiographs; end-plate diameters were measured with calipers and end-plate areas (Table 1) were measured by first photographing the end-plate along with a scale, cutting out the end-plate image along its contour and, after adjusting for scale size, calculating the area from the cutout weight. The mean distance from the superior vertebral body center to the disc center was approximately $14 \mathrm{~mm}$.

For load-displacement testing, each motion segment was mounted so that the inferior vertebra was rigidly attached to the base of a testing apparatus and the superior vertebra was free to move in response to the loads applied. The end-plates and areas of the bodies and posterior elements well away from any ligaments were scraped to remove the periosteal covering and expose areas of roughened bone. Metal screws were set

Table 1. Cervical motion segment descriptive data

\begin{tabular}{|c|c|c|c|c|c|c|c|c|c|}
\hline \multirow[b]{2}{*}{ Segment } & \multirow[b]{2}{*}{$\begin{array}{l}\text { Spine } \\
\text { no. }\end{array}$} & \multirow[b]{2}{*}{$\begin{array}{l}\text { Spine } \\
\text { level }\end{array}$} & \multicolumn{2}{|c|}{$\begin{array}{l}\text { Tested with } \\
\text { posterior } \\
\text { elements }\end{array}$} & \multirow{2}{*}{$\begin{array}{c}\text { Disc } \\
\text { height } \\
\text { (mm) }\end{array}$} & \multicolumn{2}{|c|}{$\begin{array}{c}\text { Disc } \\
\text { diameters }\end{array}$} & \multirow{2}{*}{$\begin{array}{l}\text { Disc } \\
\text { area } \\
\left(\mathrm{cm}^{2}\right)\end{array}$} & \multirow[b]{2}{*}{$\begin{array}{c}\text { Degen } \\
\text { grade }\end{array}$} \\
\hline & & & & & & $\begin{array}{l}\mathbf{A}-\mathbf{P} \\
(\mathrm{mm})\end{array}$ & $\begin{array}{l}\text { Lateral } \\
(\mathrm{mm})\end{array}$ & & \\
\hline 1 & 1 & $C 2-3$ & $x$ & $x$ & 4.0 & 14.4 & 19.9 & 3.0 & 3 \\
\hline 2 & 1 & C4-5 & $x$ & $x$ & 5.0 & 15.6 & 20.1 & 3.1 & 2 \\
\hline 3 & 1 & C6-7 & $x$ & $x$ & 5.0 & 15.9 & 20.8 & 3.2 & 1 \\
\hline 5 & 4 & C $3-4$ & $x$ & $x$ & 6.0 & 18.6 & 25.6 & 4.1 & 1 \\
\hline 6 & 3 & $C 2-3$ & $x$ & $x$ & 5.0 & 18.4 & 17.1 & 3.1 & 1 \\
\hline 8 & 14 & C3-4 & & $x$ & 5.0 & 21.5 & 26.4 & 5.1 & 2 \\
\hline 10 & 17 & $\mathrm{C} 2-3$ & & $x$ & 5.0 & 14.2 & 20.4 & 2.5 & 2 \\
\hline 11 & 15 & $\mathrm{C} 2-3$ & $x$ & $x$ & 6.0 & 17.2 & 21.9 & 3.1 & 1 \\
\hline 12 & 15 & C4-5 & $x$ & $x$ & 6.0 & 18.3 & 22.4 & 4.5 & 2 \\
\hline 13 & 15 & C6-7 & & $x$ & 5.0 & 20.0 & 24.8 & 4.9 & 3 \\
\hline 14 & 16 & $\mathrm{C} 2-3$ & $x$ & & N/A & 18.2 & 21.5 & 3.7 & 2 \\
\hline 15 & 16 & $\mathrm{C} 4-5$ & $x$ & & 3.0 & 23.1 & 25.0 & 5.6 & 4 \\
\hline 16 & 16 & C6-7 & & $x$ & 3.0 & 25.6 & 30.1 & 6.0 & 4 \\
\hline 17 & 21 & C2-3 & $x$ & & N/A & 17.9 & 23.1 & 3.5 & 2 \\
\hline 18 & 21 & C4-5 & $x$ & & 4.0 & 19.2 & 23.1 & 4.8 & 3 \\
\hline 19 & 21 & C6-7 & & $x$ & 4.0 & 19.3 & 27.2 & 5.5 & 3 \\
\hline 20 & 22 & $C 2-3$ & $x$ & $x$ & 6.0 & 13.5 & 18.6 & 3.1 & 1 \\
\hline 21 & 22 & C4-5 & $x$ & $x$ & 7.0 & 15.1 & 21.1 & 3.2 & 2 \\
\hline 22 & 22 & C6-7 & $x$ & $x$ & 5.0 & 18.6 & 27.6 & 4.7 & 2 \\
\hline 23 & 23 & C2-3 & $x$ & $x$ & 3.0 & 17.0 & 23.0 & 3.8 & 4 \\
\hline 24 & 24 & C4-5 & & $x$ & 4.0 & 14.8 & 22.0 & 3.0 & 4 \\
\hline 25 & 32 & C6-7 & $x$ & & 6.0 & 18.1 & 19.9 & 3.4 & 1 \\
\hline 26 & 32 & C3-4 & & $x$ & 4.0 & 17.6 & 18.6 & 3.2 & 2 \\
\hline 27 & 35 & C $3-4$ & & $x$ & 5.0 & 18.8 & 22.5 & 3.8 & 2 \\
\hline 28 & 35 & C5-6 & & $x$ & 5.0 & 19.7 & 24.0 & 4.7 & 3 \\
\hline 29 & 35 & C7-T1 & & $x$ & 6.0 & 19.7 & 31.0 & 5.9 & 3 \\
\hline 30 & 34 & C2-3 & & $x$ & 3.0 & 18.2 & 22.7 & 4.3 & 3 \\
\hline 31 & 34 & C5-6 & & $x$ & 3.0 & 18.5 & 24.0 & 4.8 & 4 \\
\hline 32 & 34 & C7.T1 & & $x$ & 7.0 & 19.4 & 25.4 & 4.8 & 2 \\
\hline 33 & 31 & C3-4 & & $x$ & 3.0 & 15.8 & 23.4 & 4.4 & 3 \\
\hline 34 & 31 & C5-6 & & $x$ & 3.0 & 16.1 & 25.0 & 4.7 & 3 \\
\hline 35 & 31 & C7-T1 & & $x$ & 5.0 & 16.4 & 26.3 & 4.8 & 2 \\
\hline 36 & 36 & C3-4 & & $x$ & 3.0 & 15.2 & 17.1 & 2.8 & 3 \\
\hline 37 & 36 & C5-6 & & $x$ & 4.0 & 15.4 & 18.4 & 3.3 & 4 \\
\hline \multirow[t]{3}{*}{38} & 36 & C7-T1 & & $x$ & 4.0 & 16.8 & 26.7 & 4.2 & 3 \\
\hline & & & & Mean & 4.6 & 17.8 & 23.1 & 4.1 & 2.5 \\
\hline & & & & S.D. & 1.2 & 2.5 & 3.4 & 1.0 & 1.0 \\
\hline
\end{tabular}


in holes drilled into the upper and lower end-plates and into the superior and inferior facets of the superior and inferior vertebrae respectively. The screws were inserted to a depth of not more than $6 \mathrm{~mm}$ and were adjusted until the mid-plane of the disc was approximately horizontal in the test fixture. The segment was then centered on a circular aluminum plate by aligning the disc center (located at the intersection of the anteroposterior and lateral disc diameters) with the plate center. Liquid methylmethacrylate cement was poured into a well around the motion segment to within $1 \mathrm{~cm}$ of the disc and allowed to harden. The segment-with-plate was then inverted and the disc levelled as before. The segment was centered on a second, upper plate; methylmethacrylate cement was again poured and permitted to harden.

The mounted segment was bolted to a cylinder set upon a platform within a frame (Fig. 1). The cylinder, which could be rotated to four positions about its vertical axis, together with a set of pulleys mounted upon the frame, allowed for all modes of loading. The testing apparatus used was modified from that previously described by Schultz et al. (1979) and was similar to that described by Panjabi et al. $(1976,1981)$.

A cylindrical crown-piece with a mass of $2.5 \mathrm{~kg}$ was bolted to the upper plate, from which four loading arms projected horizontally outwards and downwards in the sagittal and frontal planes. These arms were drilled to permit the attachment of load-application cords, so that loads could be applied in effect at the center of the intervertebral disc of the mounted segment. Three of the four steel balls on the upper

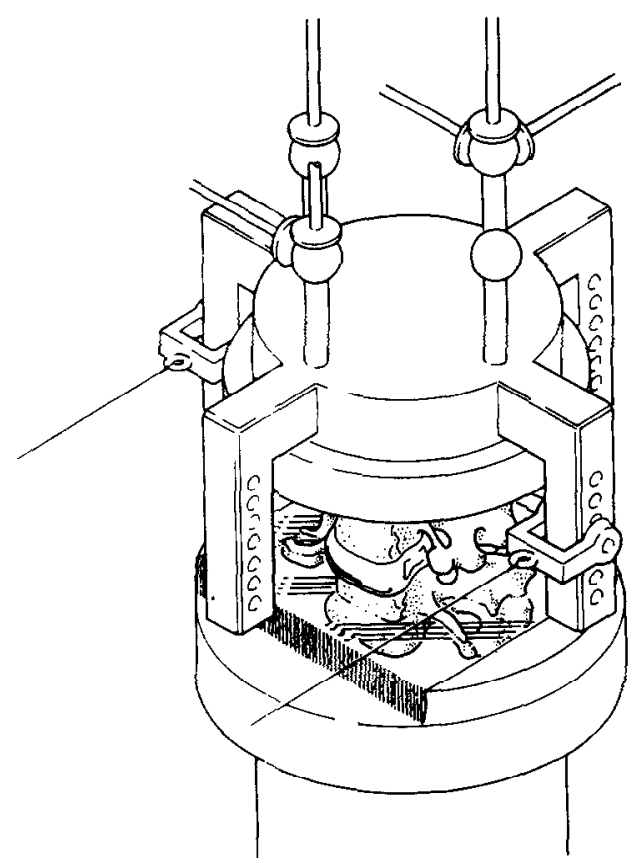

Fig. 1. Schematic of an intact motion segment being tested in anterior shear. The six dial gauge plungers contact three of the crownpiece balls. They are used to measure the six components of the motion of the superior vertebra. surface of the crown-piece provided points of reference for the measurement of motions of the upper vertebral body.

Six mechanical dial gauges were aligned with a motion segment reference frame, the axes of which were positive to the left, posterior and superior. Three gauges were mounted vertically, two were placed horizontally but opposite to each other and the remaining gauge was placed horizontally and mutually perpendicular to the other five. This permitted the measurement of all six components of segment motion. A computer program supplied with ball locations and motion segment dimension data was used to calculate the three displacements of the geometrical center of the superior vertebral body and the three body rotations, using the theory of three-dimensional rigid body kinematics. A local environment of $100 \%$ relative humidity and $20^{\circ} \mathrm{C}$ temperature was maintained around the segment throughout testing.

A pair of cables attached from opposite loading arms of the crown-piece to pneumatic cylinders in the base of the frame was used to apply an initial compression load. Cable tension was controlled by pressurized nitrogen and measured by means of load cells. Compression loads in increments of $9.8 \mathrm{~N}$, up to a maximum of $49.0 \mathrm{~N}$, were applied at the disc center. Once this magnitude of compression was reached, it was maintained along with the weight of the crownpiece as a 'preload' throughout the remainder of the tests. The presence of a preload is known to affect the load-displacement responses of lumbar motion segments increasing the load-displacement response in some modes of loading and decreasing it in others (Panjabi et al., 1977); this preload simulated the in vivo loading due to head weight.

The moment generated by the weight of the crownpiece in eccentric positions was small compared with the magnitude of the applied bending moments. If, for example, a motion segment bending rotation of $5^{\circ}$ occurred, the crown-piece moment resulting from it was on the order of $0.08 \mathrm{Nm}$, while the moments applied to produce such rotations were typically in the range of $1.2-2.2 \mathrm{Nm}$.

The other loadings were achieved using pairs of cables attached to the two remaining free arms of the crown-piece. These cables were dead-weight loaded. When the applied cable forces were oppositely directed, flexion, extension, right lateral bending, or (when viewed from above) counterclockwise torsion moments were produced about the mid-point of the disc. When the cable forces were similarly directed, anterior, posterior, or right lateral shearing forces were produced at the level of the disc mid-plane.

A preliminary load/unload cycle without measurements was performed in each mode to determine the load level necessary to produce small translations (approximately $1 \mathrm{~mm}$ ) or small rotations (approximately $5^{\circ}$ ). The $49 \mathrm{~N}$ compression preload was again applied and initial dial gauge readings were taken in the preloaded state. The additional loads were applied in 
four increments. For intact segments, these loads ranged from 0.98 to $2.16 \mathrm{Nm}$ in bending and torsion and from 10 to $39 \mathrm{~N}$ in shear. For disc segments, these loads ranged from 0.39 to $1.57 \mathrm{Nm}$ in bending and axial torsion and from 4 to $16 \mathrm{~N}$ in shear. Gauge readings were taken starting $30 \mathrm{~s}$ after each load increment was applied.

While all six components of the motion of the upper vertebral body center were calculated, only the principal motions were used to characterize the stiffness properties of the motion segments. The principal motion is the translation along the line of action of the force in compression or shear, or the rotation about the axis of the applied moment in bending or axial torsion. The coupled motions are the five other motions of translation and rotation which accompany the principal motion.

Load applications were repeated for one motion segment, once in compression and twice in right lateral bending. In compression, the principal motions were reproducible within $25 \%$ and, in bending, the principal motions were reproducible within $10 \%$.

The segment load-displacement data pairs were linearly regressed for each principal motion in each mode of loading. The slope of the regression line was defined as the average stiffness in a given mode of loading; this is equal to the inverse of the matrix flexibility coefficient, but not to the matrix stiffness coefficient. Because the presence of a neutral zone might have affected the linearity of the loaddisplacement curve, a tangent stiffness was also computed, without including the initial load-displacement data pairs. In all but two of the 16 cases, the tangent stiffnesses were within $20 \%$ of the average stiffnesses. Data from the two segments which exhibited a bony union of the facets were not included in the compu- tations of the mean stiffnesses. The results for these segments will be presented separately. Standard deviations were calculated if stiffnesses of three or more segments were available.

To see if the variations among individual results (Fig. 2) could be reduced if the differences in segment dimensions were taken into account, an analysis similar to that of Berkson et al. (1979) was performed. The ratio of disc area $(a)$, frontal plane diameter $(f)$, sagittal plane diameter $(s)$ and height $(h)$ to the respective population mean was determined for each segment. In light of the technical theory of the bending of a homogeneous linear elastic elliptical disk, the ratios of the quantities

$$
a / h ; f^{2} a / h^{2} ; s^{2} a / h^{2} \text { and } a\left(s^{2}+f^{2}\right) / h
$$

to their respective population means were also computed. The motion of each segment was multiplied by each of the appropriate ratios. Then, the stiffnesses were recomputed using these normalized motions. The coefficient of variation $(\mathrm{CV})$ of the normalized stiffnesses was then compared with the $C V$ of the actual stiffnesses. $C V$ is defined as the ratio of the standard deviation to the mean.

All segments, with or without posterior elements, were loaded incrementally in either flexion, extension, or right lateral bending until failure occurred. Failure was considered to have occurred when a load increment produced frank rupture of the segment or impact of the crown-piece with other parts of the test apparatus. This usually occurred when rotations exceeded $10^{\circ}$. In some cases failure was rapid, occurring with a loud snap; in others, it was more gradual. A bubble goniometer mounted on the crown-piece in failure testing recorded the main rotations. Eight loadings terminated due to mounting failure. This

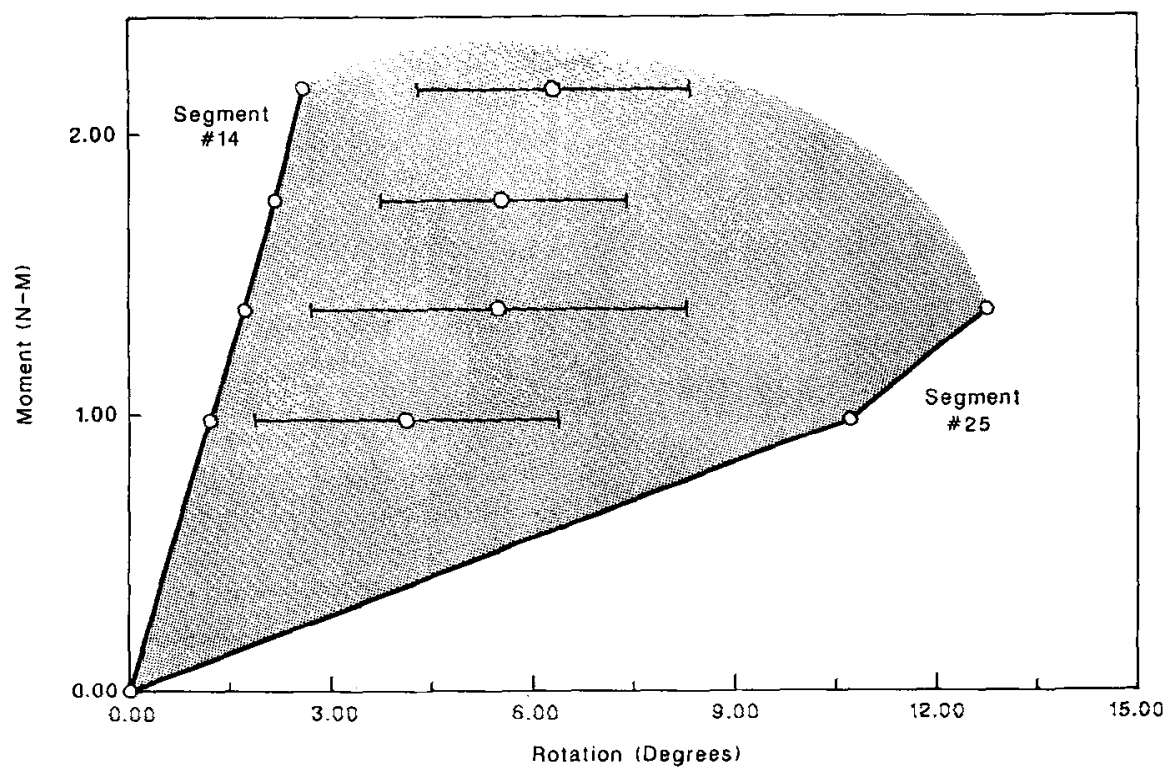

Fig. 2. Moment vs rotation responses in flexion. The bars indicate mean values and standard deviations. The shaded area shows the range of the data. 
occurred either because the screws in the upper end plate of the superior vertebral body tore loose from the bone, or because the methylmethacrylate cement adhering to the segment-with-screws tore free from its attachment to the lower mounting plate.

\section{RESULTS}

In response to the application of bending and torsional moments, the motion segments displayed the smallest principal motions in torsion and the largest in flexion (Table 2). In response to shear loads, the largest principal motions were seen in posterior shear. Disc segments generally responded with larger displacements than intact segments.

The chief coupled motions, observed for both intact and disc segments (Table 2), included anterior translation of the superior vertebral body in response to a flexion moment, posterior translation in response to an extension moment, right translation and clockwise torsion in response to a right lateral bending moment, and left bending and translation in response to a counterclockwise torsion moment. Compression and shear forces did not produce significant coupled motions.

The mean stiffnesses calculated for the motion segments are detailed in Table 3 for both intact and disc segments. Stiffnesses calculated from loaddeformation curves slopes (tangent stiffnesses) were almost always within $20 \%$ of the regression line slope stiffnesses. Removal of the posterior arches decreased the mean motion segment stiffnesses by approximately $50 \%$ in all modes of loading except posterior shear.

Normalization of the stiffnesses with respect to either disc areas, heights, or diameters did not consistently reduce the $C V \mathrm{~s}$ in all eight loading modes. Normalization by means of each of the four computed ratios was even less effective and altered data variation for only a few loading modes. Sixty per cent of the observed $C V$ reductions occurred among the disc segment stiffnesses, especially among the shear stiffnesses. The $C V \mathrm{~s}$ in some modes of loading, flexion, for example, were reduced by only one normalization, whereas in others, such as anterior shear, over half of the normalizations led to some reduction.

There was no clear dependence of the motion segment stiffness on the disc level in either intact or disc segments; this was consistent with the results of Nachemson et al. (1979) for lumbar motion segments and of Panjabi et al. (1986) for cervical motion segments. Neither was there any clear dependence of stiffness on the degree of degeneration in the intact segments for any mode of loading or in the disc segments in bending or torsion modes. Disc segments with more degenerated discs (Grades 3 or 4) did however, show approximately a $50 \%$ reduction in mean stiffness in compression and an approximately three-fold increase in mean stiffness for all shear modes (Table 4). This reduction in compression stiffness is consistent with the results of Hirsch and Nachemson (1954) and of Nachemson et al. (1979) for lumbar motion segments.

The mechanical behavior of the two segments that exhibited a bony union of the posterior facets was grossly different from that of the other segments in that motions were very small. In most cases, the stiffnesses of these two segments (Table 5) were five-ten times greater than those of the other segments. One of the segments, while intact, moved negligibly under its compression load.

Five intact motion segments and 27 disc segments were loaded to failure (Table 6). One intact segment, while undergoing load-displacement testing, failed spontaneously at $3.9 \mathrm{Nm}$ in extension; another failed in flexion at $3.1 \mathrm{Nm}$. Failure data were unavailable for three segments. When mounting failures occurred, the moment last applied was interpreted as a lower limit to the segment failure moment. Since these values were included in the computations of the mean failure moments, those mean moments should be regarded as lower bounds. The load-displacement relationship remained approximately linear to the point of failure. Disc segments failed both in flexion and extension at similar moment levels (approximately $3.4 \mathrm{Nm}$ ). These failure moments appeared to be significantly smaller than the failure moment in right lateral bending, but an insufficient number of segments was tested in that mode for an evaluation of significance. In extnsion, the failure moment was greater for intact segments than for disc segments; this might have resulted from impingement of the posterior arches. The disc segments from the facet bony union specimens each had significantly higher failure moments in extension (5.9 Nm and $10.4 \mathrm{Nm}$, respectively) than the remainder of the disc population. In the latter case, the failure moment represented a mounting failure.

\section{DISCUSSION}

Wide variations in mechanical properties of connective tissues tend to be the norm; the inter-individual variation in the load-displacement responses and the inability to significantly reduce the measured variations by normalization with respect to disc dimensions found here is characteristic of experiments of this type (Berkson et al., 1979, for example). Factors relating to experimental design, e.g. the position of the loading axes, permanent deformation of a motion segment in the course of a sequence of mechanical tests, changes in intradiscal pressure and soft tissue creep may all have an effect of tending to increase the $C V$ of experimentally determined mechanical properties (Tencer and Ahmed, 1981).

In general, the cervical rotations reported in Table 2 are of similar magnitude to the intersegmental ranges of motion reported by Lysell (1969). For example, the combined mean principal motions in flexion and extension $\left(9.7^{\circ}\right)$ corresponded to $91 \%$ of the mean 


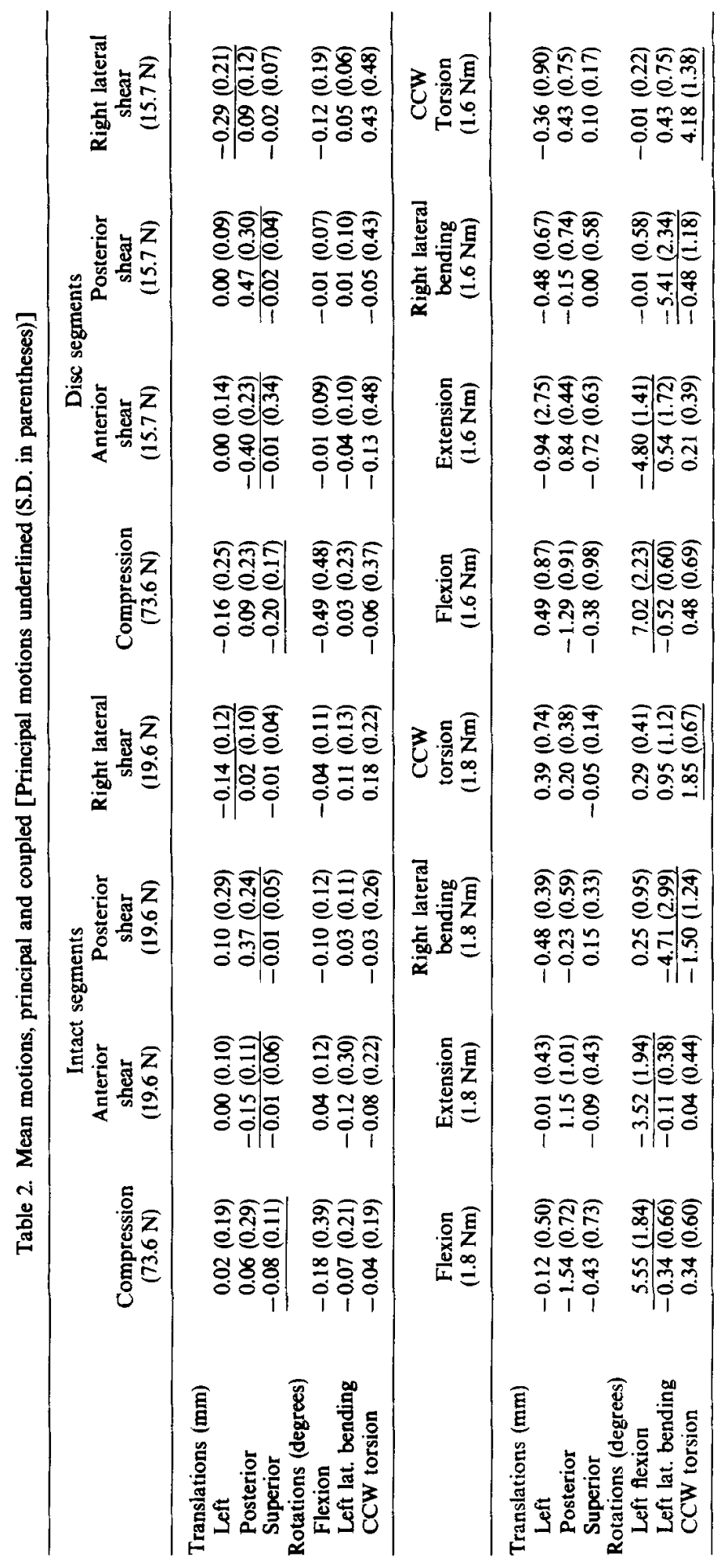


Table 3. Mean motion segment stiffnesses

\begin{tabular}{lcc}
\hline Loading mode & Stiffness & \multicolumn{1}{c}{ Range } \\
\hline Intact segments & & \\
Compression & $1318(1170) \mathrm{N} \mathrm{mm}^{-1}$ & $116-3924 \mathrm{~N} \mathrm{~mm}^{-1}$ \\
Anterior shear & $131(157)$ & $29-631$ \\
Posterior shear & $49(24)$ & $15-96$ \\
Right lateral shear & $119(65)$ & $28-226$ \\
Flexion & $0.43(0.23) \mathrm{Nm} \mathrm{degree}^{-1}$ & $0.10-0.83 \mathrm{Nm} \mathrm{degree}^{-1}$ \\
Extension & $0.73(0.45)$ & $0.26-1.80$ \\
Right bending & $0.68(0.49)$ & $0.19-1.58$ \\
CCW torsion & $1.16(0.46)$ & $0.64-2.02$ \\
Disc segments & $492(472) \mathrm{N} \mathrm{mm}^{-1}$ & $57-2060 \mathrm{~N} \mathrm{~mm}^{-1}$ \\
Compression & $62(63)$ & $12-317$ \\
Anterior shear & $50(36)$ & $13-169$ \\
Posterior shear & $73(62)$ & $17-267$ \\
Right lateral shear & $0.21(0.14) \mathrm{Nm} \mathrm{degree}^{-1}$ & $0.05-0.65 \mathrm{Nm} \mathrm{degree}^{-1}$ \\
Flexion & $0.32(0.15)$ & $0.06-0.78$ \\
Extension & $0.33(0.18)$ & $0.09-0.91$ \\
Right bending & $0.42(0.17)$ & $0.23-0.93$ \\
CCW torsion & & \\
\hline
\end{tabular}

S.D. in parentheses.

Table 4. Stiffnesses $\left(\mathrm{N} \mathrm{mm}^{-1}\right)$ by degeneration grade disc segments

\begin{tabular}{lcccc}
\hline Grade & Compression & $\begin{array}{c}\text { Anterior } \\
\text { shear }\end{array}$ & $\begin{array}{c}\text { Right lateral } \\
\text { shear }\end{array}$ & $\begin{array}{c}\text { Posterior } \\
\text { shear }\end{array}$ \\
\hline All & $492(472)$ & $62(63)$ & $73(62)$ & $50(36)$ \\
1 & {$[28]$} & {$[27]$} & {$[25]$} & {$[26]$} \\
& $737(885)$ & $31(13)$ & $32(12)$ & $18(7)$ \\
2 & {$[4]$} & {$[4]$} & {$[4]$} & {$[3]$} \\
& $603(473)$ & $39(24)$ & $72(73)$ & $40(24)$ \\
3 & {$[11]$} & {$[11]$} & {$[11]$} & {$[11]$} \\
& $320(249)$ & $99(96)$ & $82(66)$ & $72(46)$ \\
4 & {$[10]$} & {$[9]$} & {$[7]$} & {$[9]$} \\
& $328(236)$ & $76(18)$ & $114(19)$ & $53(26)$ \\
& {$[3]$} & {$[3]$} & {$[3]$} & {$[3]$} \\
\hline
\end{tabular}

S.D. in parentheses.

Number of specimens in brackets.

Table 5. Stiffness $\left(\mathrm{N} \mathrm{mm}^{-1}, \mathrm{Nm} \mathrm{deg}^{-1}\right)$ of segments with facet bony unions

\begin{tabular}{lcccccccc}
\hline & Compression & $\begin{array}{c}\text { Anterior } \\
\text { shear }\end{array}$ & $\begin{array}{c}\text { Right } \\
\text { lateral } \\
\text { shear }\end{array}$ & $\begin{array}{c}\text { Posterior } \\
\text { shear }\end{array}$ & Flexion & $\begin{array}{c}\text { Right } \\
\text { lateral } \\
\text { bending }\end{array}$ & Extension & Torsion \\
\hline $\begin{array}{l}\text { Intact } \\
\begin{array}{l}\text { Segment 23 } \\
\text { Disc }\end{array}\end{array}$ & $*$ & 726 & 280 & 740 & 7.06 & 10.96 & 9.17 & 14.13 \\
$\begin{array}{l}\text { segment 23 } \\
\text { Disc }\end{array}$ & 897 & 842 & $\mathrm{~N} / \mathrm{A}$ & 280 & 0.80 & 1.22 & 0.32 & 0.48 \\
segment 24 & 2944 & 568 & 760 & 724 & 2.76 & 3.97 & 2.65 & 8.78 \\
\hline
\end{tabular}

* Motion was negligible.

intersegmental sagittal range of motion $\left(10.7^{\circ}\right)$ reported by Lysell (1969); the mean principal motion in right lateral bending $\left(4.7^{\circ}\right)$, if combined with an equal symmetric motion in left lateral bending, corresponded to $112 \%$ of the mean intersegmental frontal range of motion $\left(8.4^{\circ}\right)$. However, the mean principal motion in counterclockwise rotation $\left(1.9^{\circ}\right)$, if combined with an equal symmetric motion in clockwise rotation, corresponded to $51 \%$ of the mean intersegmental hori- zontal range of motion $\left(7.4^{\circ}\right)$, suggesting that larger twisting moments might have been tolerated by the motion segments. Since Lysell (1969) reported only kinematic results, no inferences can be drawn with respect to the load levels applied here.

When the data of Panjabi et al. (1986) and the data of this study are linearly scaled to permit estimations of the mean displacements produced by prescribed shear and compression loads (Table 7), it is seen that the 
Table 6. Moments required to produce segment failure

\begin{tabular}{ccc}
$\begin{array}{c}\text { Number and } \\
\text { type of } \\
\text { segments }\end{array}$ & $\begin{array}{c}\text { Failure } \\
\text { mode }\end{array}$ & $\begin{array}{c}\text { Mean moment } \\
\text { at failure } \\
(\mathrm{Nm})\end{array}$ \\
\hline 5 (intact) & Ext & $5.8(3.9)$ \\
16 (disc) & Ext & $3.2(1.8)$ \\
8 (disc) & Flx & $3.5(1.4)$ \\
1 (disc) & RLB & 8.2 \\
No. 23 (disc) & Ext & 5.9 \\
No. 24 (disc) & Ext & 10.4 \\
\hline
\end{tabular}

S.D. in parentheses.

Table 7. Comparison of mean predicted approximate displacements produced by a $50 \mathrm{~N}$ prescribed load on intact cervical motion segments

\begin{tabular}{lcc} 
& \multicolumn{2}{c}{ Displacements } \\
Panjabi et & This \\
al. (1986) & study \\
\hline Compression & $0.6 \mathrm{~mm}$ & $0.05 \mathrm{~mm}$ \\
Anterior shear & $1.9 \mathrm{~mm}$ & $0.4 \mathrm{~mm}$ \\
Posterior shear & $1.6 \mathrm{~mm}$ & $0.9 \mathrm{~mm}$ \\
Right lateral shear & $1.5 \mathrm{~mm}$ & $0.4 \mathrm{~mm}$ \\
\hline
\end{tabular}

Displacements linearly scaled from data of this study and of Panjabi et al. 1986.

shear displacements in this study's population of intact motion segments are lower by factors of 1.8-4.8; similarly, the compression displacements are lower by an order of magnitude. Differences in experimental technique between the studies were evident in the application of shear loads; these may in part account for the differences in measured displacements between the motion segment populations.

In the study of Panjabi et al. (1986), the shear loads were applied at the level of the superior vertebral body center with a $9.7 \mathrm{~N}$ preload. Thus, because the shear load also induces a bending moment proportional to the half height of the vertebra, this was in reality a combined shear and bending test, with the bending moment tending to increase the apparent shear displacements. In the present study, the shear loads were applied at the midplane of the disc with a $73.6 \mathrm{~N}$ preload. This method of loading had a negligible associated bending moment and yielded the direct stiffness of the disc under a pure shear loading, combined with compression. It is therefore not surprising that the present study yielded shear stiffnesses several times larger than those found by Panjabi et al. (1986). In the case of compression loading, it is less clear how the experimental techniques differed. Generally, the $C V \mathrm{~s}$ in this study, for both displacements and stiffnesses, tended to be large, often approaching or exceeding unity. Although a relationship between degeneration grade and compression stiffness was not observed for intact motion segments in this study, it may be noted that the disc population in the study of Panjabi et al. (1986) had a mean degeneration grade (and standard deviation) of $3.3(0.8)$, whereas the disc population in this study had a mean degeneration grade of $2.5(1.0)$.

It is interesting to compare the load-displacement responses of cervical and lumbar motion segments. When the data of Berkson et al. (1979) and Schultz et al. (1979) and the data of this study are linearly scaled to permit estimations of the loads required for prescribed motion segment displacements (Table 8), it is seen that, with the exception of intact segment compression, the same principal motions are produced in cervical motion segments by significantly smaller loads than are required for lumbar motion segments. The main exceptions to this pattern are the cases of intact segment compression and lateral shear, where the load magnitudes are nearly equal. Removal of the posterior elements uniformly lowered the required load for the same displacement in the cervical segments while, in the lumbar segments, posterior element excision had little effect on compression, right lateral shear, and right lateral bending results.

In this study, removal of the cervical posterior elements approximately doubled compression displacements. In contrast, Berkson et al. (1979) reported no significant increase in lumbar compression displacements with posterior element excision. Cervical facets are inclined approximately $45^{\circ}$ to both the longitudinal and anterioposterior axes of the vertebra, while lumbar

Table 8. Comparison of approximate cervical and lumbar loads required to produce a prescribed displacement

\begin{tabular}{llrrrr}
\hline Mode & $\begin{array}{c}\text { Principal } \\
\text { motion }\end{array}$ & \multicolumn{1}{c}{$\begin{array}{c}\text { Intact segments } \\
\text { lumbar }\end{array}$} & $\begin{array}{c}\text { Disc segments } \\
\text { cervical } \\
\text { load }\end{array}$ & $\begin{array}{c}\text { lumbar } \\
\text { load }\end{array}$ & $\begin{array}{c}\text { cervical } \\
\text { load }\end{array}$ \\
\hline Compression & $0.1 \mathrm{~mm}$ & $78.2 \mathrm{~N}$ & $92.0 \mathrm{~N}$ & $86.0 \mathrm{~N}$ & $39.9 \mathrm{~N}$ \\
Anterior shear & $1.0 \mathrm{~mm}$ & $143.3 \mathrm{~N}$ & $91.2 \mathrm{~N}$ & $91.5 \mathrm{~N}$ & $39.3 \mathrm{~N}$ \\
Posterior shear & $1.0 \mathrm{~mm}$ & $145.8 \mathrm{~N}$ & $40.0 \mathrm{~N}$ & $102.4 \mathrm{~N}$ & $33.4 \mathrm{~N}$ \\
Right lateral shear & $1.0 \mathrm{~mm}$ & $128.4 \mathrm{~N}$ & $115.3 \mathrm{~N}$ & $113.2 \mathrm{~N}$ & $54.1 \mathrm{~N}$ \\
Flexion & $5.0^{\circ}$ & $4.6 \mathrm{Nm}$ & $1.3 \mathrm{Nm}$ & $4.0 \mathrm{Nm}$ & $0.7 \mathrm{Nm}$ \\
Extension & $2.0^{\circ}$ & $4.4 \mathrm{Nm}$ & $1.0 \mathrm{Nm}$ & $2.6 \mathrm{Nm}$ & $0.5 \mathrm{Nm}$ \\
Right lateral bending & $4.5^{\circ}$ & $4.7 \mathrm{Nm}$ & $1.7 \mathrm{Nm}$ & $4.8 \mathrm{Nm}$ & $1.1 \mathrm{Nm}$ \\
CCW torsion & $1.0^{\circ}$ & $6.8 \mathrm{Nm}$ & $1.1 \mathrm{Nm}$ & $2.7 \mathrm{Nm}$ & $0.4 \mathrm{Nm}$ \\
\hline
\end{tabular}

Loads linearly scaled from data of this study and of Berkson et al. 1979 and Schultz et al. 1979. 
facets are more nearly parallel to the longitudinal axis and perpendicular to the anterioposterior axis (White and Panjabi, 1978). Thus, in compression, the posterior facets of cervical vertebrae might be expected to carry more load, and their removal might be expected to have a larger effect on motion segment response to compressive load than in the lumbar segments.

A distinct coupling pattern of left lateral bending with counter-clockwise axial rotation and of clockwise axial rotation with right lateral bending, also noted by Lysell (1969), was observed. The ratios of principal motion to main coupled motion for right lateral bending and counterclockwise torsion (Table 2) were, respectively, 3.14 and 1.95; these fell within the corresponding ranges reported by Lysell (1969) of 1.47-7.48 and 1.14-4.00, respectively. In both cervical and lumbar segments (Tables 2 and 3; Schultz et al., 1979), similar sagittal rotations were accompanied by similar anteroposterior translations. Lateral bending rotations of cervical segments were accompanied by smaller lateral translations and larger axial rotations than were observed in lumbar segments; these lumbar axial rotations were in the opposite sense to the analogous cervical rotations. Axial torsion was accompanied by significant amounts of lateral bending only in intact cervical segments. Removal of the cervical posterior elements significantly decreased the magnitude of all coupled rotations.

No significant motion couplings were observed here in cervical segments in compression. This was similar to the findings of Berkson et al. (1979) for lumbar segments but contrasted with the results reported by Panjabi et al. (1986); in this latter case, extension and right lateral bending were coupled with compression displacements. In shear, the cervical segments of this study exhibited no significant rotations. However, Berkson et al. (1979) reported that for lumbar segments anterior shear displacements were accompanied by flexion rotations, posterior shear displacements were accompanied by extension rotations and right lateral shear displacements were accompanied by right lateral bending rotations. Panjabi et al. (1986) also reported that for cervical segments anterior shear displacements were accompanied by flexion and counterclockwise axial rotations, posterior shear displacements were accompanied by extension and clockwise axial rotations and right lateral shear displacements were accompanied by counterclockwise axial rotations. These latter results may possibly reflect differences in the point of application of these lumbar and cervical shear loads, which were at the level of the upper vertebral body center, whereas in this study they were at mid-disc level.

The mean stiffnesses of cervical motion segments were compared (Tables 9 and 10) with stiffnesses previously reported for cervical, thoracic, and lumbar segments; the variations among the reported values may be due to variations in tissue properties as well as to differences in experimental procedure. In most of those studies, stiffnesses were not reported as such; the values tabulated here were computed as mean secant stiffnesses from reported load-displacement data or curves or as reciprocals of reported flexibility coefficients.

The mean compression stiffness of intact cervical segments $\left(1310 \mathrm{~N} \mathrm{~mm}^{-1}\right)$ was similar to those reported for intact thoracic and lumbar segments (791-1928 $\mathrm{N} \mathrm{mm}^{-1}$ ); however, it was approximately one order of magnitude larger than the intact cervical compression stiffness $\left(141 \mathrm{~N} \mathrm{~mm}^{-1}\right)$ reported by

Table 9. Comparison of motion segment stiffnesses $\left(\mathrm{N} \mathrm{mm}^{-1}, \mathrm{Nm} \mathrm{deg}^{-1}\right)$

\begin{tabular}{|c|c|c|c|c|c|c|}
\hline \multirow[b]{2}{*}{ Study } & \multicolumn{4}{|c|}{ Intact segments } & \multirow{2}{*}{$\begin{array}{c}\text { Lat. } \\
\text { bending }\end{array}$} & \multirow[b]{2}{*}{ Torsion } \\
\hline & Comp. & Shear & Flexion & Extension & & \\
\hline Markolf $(1970,1972)(T 8-L 4)$ & - & - & $0.7-4.1$ & $1.4-4.8$ & $0.7-4.1$ & $\begin{array}{l}1.4-2.7^{*} \\
5.4-15.0^{t}\end{array}$ \\
\hline Panjabi (1976) (T1-T12) (2) & 1240 & 110 & 2.65 & 3.25 & 3.00 & 2.60 \\
\hline $\begin{array}{l}\text { Berkson }(1979) / \text { Schultz (1979) } \\
\quad(\text { Lumbar) }\end{array}$ & 791 & $132-158$ & 1.42 & 2.88 & 1.55 & 6.94 \\
\hline Lin (1978) (Lumbar) (4) & 1928 & $329-384$ & - & - & - & - \\
\hline $\begin{array}{l}\text { Zidel (1985) (Cervical) }{ }^{(5)} \\
\text { Panjabi (1986) (Cervical) }\end{array}$ & 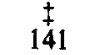 & $\begin{array}{l}23-47 \\
34-53\end{array}$ & $\begin{array}{c}0.31 \\
-\end{array}$ & 0.21 & 0.28 & 0.34 \\
\hline This study (Cervical) & 1317 & $49-131$ & 0.43 & 0.73 & 0.68 & 1.16 \\
\hline
\end{tabular}

(a) ${ }^{*}$ T8-T11. (b) ${ }^{+}$T11-L4.

(c) $\ddagger$ Flexibility reciprocal is undefined.

(1) Markolf (1970, 1972); no preload reported.

(2) Panjabi (1976); no preload reported; maximum compressive load $200 \mathrm{~N}$.

(3) Berkson/Schultz (1979); $400 \mathrm{~N}$ preload; mean secant stiffness estimated from published data.

(4) Lin (1978); no preload reported; mean secant stiffness estimated from reported load-displacement curve; maximum applied compression force, $1334 \mathrm{~N}$; maximum applied shear force, $133 \mathrm{~N}$.

(5) Zidel (1985); stiffnesses computed as reciprocals of reported flexibilities; no preload reported; maximum applied force $89 \mathrm{~N}$; maximum applied moment $3.4 \mathrm{Nm}$.

(6) Panjabi (1986); stiffnesses computed as reciprocals of reported flexibilities; $9.7 \mathrm{~N}$ preload; maximum applied force $50 \mathrm{~N}$. 
Table 10. Comparison of motion segment stiffnesses $\left(\mathrm{N} \mathrm{mm}^{-1}, \mathrm{Nm} \mathrm{deg}^{-1}\right)$

\begin{tabular}{|c|c|c|c|c|c|c|}
\hline \multirow{2}{*}{ Study } & \multirow[b]{2}{*}{ Compression } & \multicolumn{2}{|c|}{ Disc segments } & \multirow[b]{2}{*}{ Extension } & \multirow{2}{*}{$\begin{array}{l}\text { Lat. } \\
\text { bending }\end{array}$} & \multirow[b]{2}{*}{ Torsion } \\
\hline & & Shear & Flexion & & & \\
\hline Virgin (1951) (Lumbar) (1) & 1030 & - & - & - & - & -- \\
\hline Hirsch (1954) (Lumbar) (2) & 957 & - & - & - & - & - \\
\hline Brown (1957) (Lumbar) (3) & $85-1485$ & - & - & - & - & - \\
\hline Markolf $(1970,1972)$ (T8-L4) & $1230-3320$ & $105-510$ & - & - & - & - \\
\hline Lin (1978) (Lumbar) (5) & - & $202-275$ & - & - & - & - \\
\hline $\begin{array}{l}\text { Berkson (1979)/Schultz (1979) } \\
\begin{array}{l}\text { (Lumbar) (6) }\end{array}\end{array}$ & 808 & $97-122$ & 1.30 & 1.29 & 1.50 & 3.69 \\
\hline This study (Cervical) & 492 & $50-73$ & 0.21 & 0.32 & 0.33 & 0.42 \\
\hline
\end{tabular}

(1) Virgin (1951); maximum applied load: c. $4000 \mathrm{~N}$, mean secant stiffness estimated from reported loaddisplacement curves.

(2) Hirsch (1954); maximum applied load $981 \mathrm{~N}$; mean secant stiffness estimated from reported loaddisplacement curves for normal discs.

(3) Brown et al. (1957): maximum applied load: $500 \mathrm{~N}$.

(4) Markolf (1970, 1972); maximum compressive load: $670 \mathrm{~N}$; maximum shear load: $200 \mathrm{~N}$ (applied to pair of discs); no preload reported.

(5) Lin (1978); no preload reported; mean secant stiffness estimated from reported load-displacement curve; maximum applied shear force, $133 \mathrm{~N}$.

(6) Berkson/Schultz (1979): $400 \mathrm{~N}$ preload; mean secant stiffness estimated from published data.

Panjabi et al. (1986) but considerably lower than the result of Zidel et al. (1985), who reported a flexibility coefficient of 0 . The mean cervical disc segment compression stiffness was lower than most of the corresponding thoracic and lumbar stiffnesses. The magnitudes of all cervical shear stiffnesses also tended to be as much as $70-90 \%$ lower than most corresponding thoracic and lumbar-values. Zidel et al. (1985) and Panjabi et al. (1986) reported intact cervical shear stiffnesses in anterior, posterior and right lateral shear of 32,47 and $30 \mathrm{~N} \mathrm{~mm}^{-1}$ and of 34,53 and $53 \mathrm{~N} \mathrm{~mm}^{-1}$, respectively; these correspond respectively to this study's mean results of 131,49 and $119 \mathrm{~N} \mathrm{~mm}^{-1}$. In bending and torsion modes, the mean stiffnesses of cervical motion segments were as much as $90 \%$ lower than corresponding thoracic or lumbar values.

As already noted, differences in experimental technique may be responsible for some variations in collected data; differences in methods of reporting results may also impede comparison of the results of the motion segment studies. Moreover, load-displacement properties of connective tissues tend to be nonlinear; tissue stiffness will then vary with the applied loading level.

The presence of cervical disc degeneration did not appear to affect the mean stiffnesses of intact segments or of disc segments in bending or axial torsion. However, the presence of a bony union of the facets, which was associated with a Grade 4 disc degeneration, was accompanied by approximately an order of magnitude increase in stiffnesses for nearly all loading modes. Even with removal of the posterior elements, the disc segments had stiffnesses substantially greater than those of the remainder of the specimens.

Farfan et al. (1970) reported failure of intact lumbar segments in torsion at a mean moment of $88 \mathrm{Nm}$. Miller et al. (1986) noted that intact lumbar segments showed no signs of failure in lateral bending, extension, or axial torsion at bending moments below $59 \mathrm{Nm}$. These values are approximately one order of magnitude larger than the moments that produced failure in cervical segments in the present study. The lumbar segments in both studies had mean sagittal and frontal disc diameters of approximately 38 and $53 \mathrm{~mm}$ respectively; the cervical segments in this study had corresponding mean diameters of 18 and $23 \mathrm{~mm}$. The smaller dimensions of the cervical motion segments may explain this finding in part. A difference in loadsharing effects between disc and facets, which may be due to geometric differences between the regions, may also possibly play some role.

\section{CONCLUSIONS}

(1) Motion coupling patterns of cervical motion segments were generally similar to those previously reported for lumbar segments. For example, in sagittal and lateral bending, anteroposterior and lateral shear displacements were observed respectively. However, the magnitude of the axial rotation associated with lateral bending was larger for intact cervical segments than for intact lumbar segments and in the opposite direction. Neither compression nor shear displacements were accompanied by any significant coupled motions.

(2) Cervical motion segments in bending and axial torsion exhibited lower stiffnesses than did lumbar motion segments. This was also true for shear loads, though to a lesser degree. In contrast, compression stiffnesses of intact cervical and lumbar segments were similar.

(3) Removal of the posterior elements tended to increase all mean principal motions and so decrease segment stiffnesses. Cervical disc segments were as much as $50 \%$ less stiff than intact segments in all modes 
of loading except posterior shear, where this effect was not evident. Previous studies of lumbar motion segments reported similar reductions in anteroposterior shear, lateral shear and extension stiffnesses upon removal of posterior elements.

(4) No relationship of cervical motion segment stiffness to disc level was evident. This was similar to findings in previous studies of cervical and lumbar motion segments.

(5) Severely degenerated cervical disc segments were $50 \%$ less stiff in compression and three times more stiff in shear than were less-degenerated segments. No other relationship of stiffness to degree of degeneration was noted. Lumbar motion segments also exhibit this decrease in compression stiffness with degeneration.

(6) A bony union of the facets was observed in two segments. It significantly reduced motions in response to loading. One intact motion segment was virtually incompressible. The isolated discs from both segments had stiffnesses in most modes of loading one order of magnitude greater than those of the remainder of the disc segment population.

(7) Large variations in load-displacement properties were observed in the motion segments of this study. Normalization of experimental results, based on disc areas, heights, or diameters, seldom reduced these variations.

(8) The moments required for bending failure of cervical motion segments were approximately one order of magnitude lower than those required for failure of lumbar motion segments.

Acknowledgements - The support of a Research Fellowship from the Foundation for Chiropractic Education and Research and of Public Health Service Grants NS 20536 and $\mathrm{OH} 01962$ for this research, as well as the assistance of John Duff, Karol Haderspeck-Grib and David Warwick is gratefully acknowledged.

\section{REFERENCES}

Berkson, M. H., Nachemson, A. L. and Schultz, A. B. (1979) Mechanical behavior of human lumbar spine motion segments-Part II. Responses in compression and shear; influences of gross morphology. J. biomech. Engng 101, $53-57$.

Brown, T., Hanson, R. and Yorra, A. (1957) Some mechanical tests on the lumbo-sacral spine with particular references to the intervertebral disc. $J$, Bone $J t$ Surg. 39A, 1135-1164.

Farfan, H. F., Cossette, J. W., Robertson, G. H., Wells, R. V. and Kraus, $H$. (1970) The effects of torsion on the lumbar intervertebral joint: the role of torsion in the production of disc degeneration. J. Bone Jt Surg. 52A, 468-497.

Hirsch, C. and Nachemson, A. L. (1954) A new observation on the mechanical behavior of lumbar discs. Acta orthop. scand. 23, 254-283.

Lin, H. S., Liu, Y. K. and Adams, K. H. (1978) Mechanical response of the lumbar intervertebral joint under physiological (complex) loading. J. Bone Jt Surg. 60A, 41-55.

Lysell, E. (1969) Motion in the cervical spine. Acta orthop. scand. Supp. 123.

Markolf, K. L. (1970) Stiffness and damping characteristics of the thoracic-lumbar spine. Proceedings of Workshop on Bioengineering Approaches to the Problems of the Spine, NIH, pp. 39-142.

Markolf, K. L. (1972) Deformation of the thoracolumbar intervertebral joints in response to external loads. J. Bone Jt Surg. 54-A, 511-533.

Miller, J. A. A., Schultz, A. B., Warwick, D. N. and Spencer, D. L. (1986) Mechanical properties of lumbar spine motion segments under large loads. J. Biomechanics 19, 79-84.

Nachemson, A. L. (1960) Lumbar intradiskal pressure. Acta orthop. scand. Supp. 43.

Nachemson, A. L., Schultz, A. B. and Berkson, M. H. (1979) Mechanical behavior of human lumbar spine motion segments-influence of age, sex, disc level and disc degeneration. Spine 4, 1-8.

Panjabi, M. M. Brand, R. A. and White. A. A. (1976) Threedimensional flexibility and stiffness properties of the human thoracic spine. J. Biomechanics 9, 185-192.

Panjabi, M. M., Krag, M. H., White, A. A. and Southwick, W. O. (1977) Effect of preload on load-displacement curves of the lumbar spine. Orthop. Clin. North Am. 8, 181-192.

Panjabi, M. M., Krag, M. H. and Goel, V. K. (1981) A technique for measurement and description of threedimensional six degree-of-freedom motion of a body joint with an application to the human spine. J. Biomechanics 14, 447-460.

Panjabi, M. M., Summers, D. J., Pelker, R. R. and Southwick, W. O. (1983) Three-dimensional load-displacement curves of the cervical spine. Trans. Cervic. spine Res. Soc. 11, 152-161.

Panjabi, M. M., Krag, M. H. and Chung, T. Q. (1984) Effect of disc injury on mechanical behavior of the spine. Spine 9. 707-713.

Panjahi, M. M., Summers, D. J., Pelker, R. R., Videman, T., Friedlaender, G. E. and Southwick, W. O. (1986) Threedimensional load-displacement curves due to forces on the cervical spine. J. orthop. Res. 4, 152-161.

Schultz, A. B., Warwick, D. N. and Berkson, M. H. (1979) Mechanical properties of human lumbar spine motion segments-Part I: responses in flexion, extension, lateral bending and torsion. J. biomech. Engng 101, 46-52.

Tencer, A. F and Ahmed, A. M. (1981) The role of secondary variables in the measurement of the mechanical properties of the lumbar intervertebral joint. J. biomech. Engng 103, 129-137.

Virgin, W. (1951) Experimental investigations into the physical properties of the intervertebral disc. J. Bone. Jt Surg. 33B, 607-611.

White, A. A. and Panjabi, M. M. (1978) Clinical biomechanics of the spine, p. 22. J. B. Lippincott Co., Philadelphia, PA.

Zidel, P., Ngai, J., Raynor, R., Hobbs, G. and Pugh, J. (1985) Three-dimensional analysis of cervical spine motion segments by computer videophotogrammetry. Trans. Orthop. Res. Soc. 10, 330 